\title{
North Atlantic fishy feminists and the more-than-human approach: a conversation
}

Knott Christine ${ }^{1, *}$, Power Nicole ${ }^{1}$, Neis Barbara ${ }^{1}$, Frangoudes Katia ${ }^{2}$

${ }^{1}$ Department of Sociology, Memorial University, St. John's, NL, Canada

2 University of Brest, IFREMER, CNRS, UMR 6308 AMURE, IUEM, 29280 Plouzané, France

* Corresponding author : Christine Knott, email address : christine.knott@mun.ca

\begin{abstract}
:
Fisheries and aquaculture have been the subject of feminist research and activism globally for decades. The result is a rapidly expanding body of literature examining women and fisheries and gender relations from oceans to plate. This body encompasses diverse and substantive critiques of mainstream fisheries research, policy and practice that ignore women's contributions showing how local practices, political economies and state policies (re)produce gender inequalities around access to fisheries resources and related wealth. Their work has had positive results. Some fishy feminist work draws on ecofeminism and feminist political ecology to explore links between resource degradation, neoliberal capitalism and patriarchy, but more needs to be done. This paper places existing North Atlantic feminist fisheries research in conversation with an emerging body of feminist scholarship interrogating human-fish relations. It makes the case for applying an ecofeminist lens in future work foregrounding how relations among humans, fisheries and fish are shaped by intersecting capitalist, colonial, speciesist and patriarchal systems of oppression. This lens would highlight the multiple oppressions that arise from altered fishery and aquaculture arrangements and dynamics in the age of the Anthropocene. Putting these bodies of work into lively conversation contributes to both the feminist fisheries/aquaculture and the more-thanhuman literatures.
\end{abstract}

Keywords : Aquaculture, ecofeminism, feminist theory, fisheries, more-than-human 


\section{Introduction}

Women comprise approximately half of fisheries workers globally (Harper et al. 2013). They are extensively involved in fisheries on or near the shore, in processing, marketing and social reproduction, but are less likely to be on boats, especially far out at sea (Probyn 2014). Over several decades, regional and global networks of scholars and activists have organized "gender and fisheries and aquaculture" conferences and generated a robust body of largely qualitative research documenting women's direct and indirect involvement in fisheries and gender dynamics in households, communities, paid work and state policies. Their work includes substantive feminist critiques of mainstream fisheries research, policy, and practice that ignore women's contributions and shows how local practices, political economies and the state (re)produce gender inequalities related to decision-making, access to fisheries resources and related wealth (e.g., Neis et al. 2005; Power, 2005; Williams 2012; Frangoudes, Gerrard, and Kleiber 2019). These feminists have used books, journal special issues, reports, films, and social media to share and compare their work (GAF 2018; Frangoudes and Gerrard 2018; Frangoudes et al. 2019; SEAFDEC 2020; Changing Tides 2001). This work helped accomplish the inclusion of the principle of gender equity and equality in the Food and Agriculture Organization's Small-scale Fisheries Guidelines and the development of a Handbook to support its implementation (FAO 2017). But much more needs to be done. Fisheries and aquaculture regulations and industry practices continue to ignore women's work and gender relations within fisheries communities and economies (Gerrard and Kleiber 2019), and mainstream fisheries research and policy still tend to equate fisheries with men, including in North Atlantic countries. The continued neglect of women in fisheries has perpetuated a "quantitative data gap" in the documentation of the full range of women's fisheries work (Kleiber et al. 2015, 548), with implications for understanding social-ecologies and attempts to manage them. 
In this paper, we engage with and build on the existing body of feminist fisheries research and activism by putting it into conversation with the more-than-human (MTH) literatures. We make a distinction between gender-based and feminist fisheries research. Gender-based research may be limited to a focus on gender differences within fisheries, while feminist approaches locate gender within larger systems of oppression (see Harrison 1995 for a discussion on this). As white (some of us settler) feminist fisheries scholars who have written largely from and about the North Atlantic and European fisheries contexts, we take North Atlantic gender-based and feminist fisheries work produced since 1980 as our starting point. This work has focused on the gendered and spatialized dimensions of paid work and life in local and regional fisheries from oceans to plate, and the production and reproduction of gender-related inequalities. While some of it has been informed by feminist political ecology and ecofeminist thinking that links environmental degradation to gender inequalities, the conceptualization of these linkages has tended to be human-centric and needs more attention (there are some notable exceptions e.g., Merchant 1997; Roach 2000). North Atlantic feminist fisheries work has also engaged less than it should have with gender diversity, and colonialism. Much mainstream fisheries research, as well as the North Atlantic feminist work on fisheries (ours included), treats fish as a resource and commodity; in other words, it takes for granted that our primary relation to fish is extractive and economic. This work gives very little consideration to the specificity of the lives of fish and other marine life except insofar as stock health affects the organization of fisheries work, human health, economics and gender relations.

This paper puts the North Atlantic feminist work into conversation with some key contributions to the more-than-human (MTH) turn in the social sciences. In the context of what scholars now call the Anthropocene - global capitalist processes marked by unprecedented pollution, the global climate crisis and mass extinction of species -- the MTH 
paradigm calls into question this approach to Nature, compelling us to rethink human and MTH relations so as to produce less destructive practices (Noorani and Brigstocke 2018). There is good reason to do this work now. Ocean ecosystems and ecologies, fishing and aquaculture industries and coastal communities in the North Atlantic are rapidly changing. The last few decades have witnessed fish stock declines and collapses that have played a role in concentrating wealth and control over fisheries in the hands of fewer fish harvesters and companies tied to fewer communities. Fishing industries, especially the processing sector, have experienced massive downsizing, market and price volatility, and enhanced competition for control over quotas. Intensive marine aquaculture is spreading rapidly throughout the North Atlantic and globally. Both fisheries and aquaculture spaces and resources are increasingly privatized, commodified and financialized, disembedding control over fisheries from communities, and increasing reliance on precarious and vulnerable workforces in harvesting, aquaculture, and processing (Knott 2016; Knott and Neis 2017; Pettersen 2019; Donkersloot et al. 2020). Coastal and fisheries communities are thus faced with dwindling control over their social and economic futures while responding to climate crisis-related impacts like coastal erosion and major weather events, and to outmigration, aging populations, and increased social inequality and precarity. These changes have serious ramifications for ecosystem dynamics, fish health, worker safety and health, community resilience, and current and future opportunities for achieving social justice (Bennett 2018; McKenzie-Sutter 2019; Magra 2019; Song and Soliman 2019; Tiller 2015; Davé 2020; Evans 2020; Moore 2020; Mutter 2020; ). They encompass significant threats to gender and intergenerational equality (Neis et al. 2013). In this context and with the launching of the international collaborative High-Level Panel for a Sustainable Ocean Economy (oceanpanel.org), there is an urgent need to apply insights from feminist and anti-oppression frameworks to identify and address issues of ethics and justice in the area of fisheries and 
aquaculture policy and practice.

As feminist fisheries scholars, we wish to incorporate MTH insights without losing our commitment to interrogating patriarchal, heteronormative, racist, classed and other systems of oppression in fisheries partly because they are connected to harming Nature. The paper thus foregrounds the work that an ecofeminist MTH lens (Gaard 2011) can do for our fisheries research and activism in the context of the Anthropocene in order to help reorient our future research and activism in ways that are more socially just for women and other marginalized groups, as well as for animals and animal communities. Our aim is to contribute to an emerging but diverse body of feminist scholarship interrogating human-fish relations (see Merchant 1999; Probyn 2014; 2015; 2016; Power 2015; Foley 2019), and more broadly to the fisheries/aquaculture literatures. At the same time, we offer a critique of the MTH literature that has ignored (eco)feminist and Indigenous insights, especially work that is universalizing. We are not alone in seeking space to think through how to extend feminist thinking to find ways to live better with fish and oceans (see Probyn, Johnston, and Lee 2020 for an interdisciplinary, international collection of work interrogating how to "sustain seas"). In the following sections, we first discuss key insights in the MTH literature and make an argument for an ecofeminist framing that maintains an ontological commitment to decenter human interests. We then provide a brief overview of selected feminist work related to fisheries and aquaculture in the North Atlantic since 1980, including work that explored environmental degradation, noting both their contributions and a key underdeveloped line of inquiry. Our review of these literatures is not meant to be exhaustive. In an effort to engage more fully in feminist and anti-colonial writing practices, we pay attention to how and who we cite (Mott and Cockayne 2017). In keeping with this, we have made a conscious effort to acknowledge academic scholarship that has been ignored - and in doing so have run up against barriers in publishing - limitations on word counts. We have tried to address this 
problem through the creation and inclusion of an Appendix (see Table 1 in Appendix A). Even so, we acknowledge that the geographical and thus social-ecological and economic context of our paper is limited to the North Atlantic, and 1990s groundfish stock collapses and their aftermath. Lastly, we discuss insights emerging from the literature on fish ontologies and feminist work on human-fish relations and reflect on how these might be used to support an ecofeminist MTH approach to research and activism in fisheries and aquaculture in the region and globally.

\section{More-than-Human ontologies}

The MTH ontological turn subsumes a range of disciplinary, methodological and conceptual approaches (e.g., actor network theory, new materialists, ecocriticism, etc.) (see Noorani and Brigstocke 2018), and is often linked to human geographer Sarah Whatmore's Hybrid Geographies (2002). Authors share in common an ontological shift in understanding human and more-than-human relations. They focus on deconstructing binaries between nature and culture, and on decentering the human subject (e.g., Latour 2018). Some explore the ways Nature is made and remade through political, economic, cultural and legal systems (e.g. Tsing 2016, Law and Lien 2016; Latour 2018, Patel and Moore 2017). Some interrogate the Anthropocene and seek to identify ways of existing that are less threatening to the future of all species on the planet. Collard et al. (2015, p. 322), for instance, state that the Anthropocene, "as a concept prompts the question of how humans ought to intervene in the environment; how to live in a multi-species world." Haraway (2008) and Tsing (2016) deconstruct liberal ideas about the autonomous and agentic human and envision a multispecies world of intra- and inter-actions where humans and other species are interdependent and entangled.

Many of the so-called "new" ideas attributed to the MTH scholarship are actually not so new. Todd (2016) delivers a pointed critique of the erasure of Indigenous cosmologies and 
scholarship so often found in the work describing this ontological insight about the nature/culture binary, as white academics present related ideas as theirs, as new, and fail to cite Indigenous academics and thinkers. Together, Indigenous and decolonial scholars remind us to be wary of universal claims about nature/culture and the Anthropocene, and instead to ground discussions of the climate crisis and remedies in place and in the context of ongoing colonialism (Sundberg 2014; Whyte, 2017). Whyte $(2017,207)$ writes, "indigenous conservation approaches aim at negotiating settler colonialism as a form of human expansion that continues to inflict anthropogenic environmental change on indigenous peoples." With a growing body of work critiquing the whiteness and universalizing tendencies in much of the MTH literature (Issacs 2016), there is a move to incorporate anti-oppression and inequalities frameworks. Some of this work borrows from ecofeminist theory, often without acknowledgment, where the interconnectedness of nature and culture has long been the subject of analysis (Gaard 2011).

\section{Ecofeminism}

The erasure of ecofeminist scholarship from much of the current MTH thinking is plausibly due to the (undeserved) negative association of ecofeminism with essentialism and calls to global veganism (Gaard 2011). Furthermore, while not all ecofeminist scholarship is concerned with the relationship between humans and non-human animals, at its core, ecofeminism combines ecological and feminist considerations. Many of the ideas associated with ecofeminism formed the basis of and were developed through social movements in the 1970s and 1980s, including the feminist, peace, and environmental movements in the global South and North. Ecofeminists offered a way to understand the connections between patriarchy, and colonial and capitalist systems that privileged (often violently) men, white people, rich people and overdeveloped countries in the global North over women, black and 
brown people, countries in the global South, and over Nature (Mies and Shiva 1993).

Ecofeminist analyses aimed to connect local experiences and contexts of inequalities and exploitation to broader, intersecting systems including patriarchy, capitalism, colonialism, and speciesism (Maina-Okori et al. 2018; Merchant 1980; Mies \& Shiva 2014; Plumwood 2000). Ecofeminist approaches challenge research that treats human activity as undifferentiated (i.e., treating all human activity as equally damaging and holding all humans equally responsible), and redirect attention to how marginalized groups are both more likely to experience the negative impacts of the Anthropocene and least likely to have control over practices and institutions that are destructive to Nature.

In the case of fisheries and aquaculture, the erasure of ecofeminist insights and the ongoing marginalization of feminist work in fisheries scholarship and at conferences, with such work often relegated to special interest issues and/or sessions, are interrelated and contribute to the neglect of intersecting systems of oppression, including colonialism and racialization, and processes that generate other social inequalities in fishing and aquaculture communities including violations of Indigenous sovereignty and rights and religious persecution. Discussions of equity and justice within the context of fisheries and aquaculture require that we conceptualize, document and find ways to address these linked oppressions, including in our relationships with nature and with the larger systemic power relations within and across societies and people.

\section{Feminist North Atlantic fisheries research on environmental degradation}

Over the past 40 years, feminist researchers have examined fisheries using a range of theoretical and methodological approaches (see Harper et al. 2013; Kleiber et al. 2015; Frangoudes et al. 2019; Szymkowiak and Rhodes-Reese 2020). Feminist research in the 1980s in North America and Europe was qualitative and ethnographic in design, highlighting 
the important (and often both invisible and unpaid) work that women did in household-based small-scale fisheries and in communities (Szymkowiak and Rhodes-Reese 2020). This body of literature documented the impacts of gender divisions of labour in fisheries, including on cultural values and identities, and on women's material dependence on men (see Porter 1985, Nadel-Klein and Davis 1988, as examples). Starting in the 1990s, North Atlantic feminist research focused on how regional fisheries were grappling with profound social-ecological crises triggered by stock collapses and fisheries closures and resulting in the restructuring of fish assemblages, fisheries, and fishing communities. In Canada, feminist researchers focused on the gendered effects of state and industry responses to groundfish stock collapses and subsequent moratoria on fishing, including understanding how policies reinforced and exacerbated existing gender inequalities in accessing fisheries income, employment and access to retraining programs (Muzynchka 1994; McGrath et al. 1995; Neis and Williams 1996; Bavington et al. 2004; Caicedo 2004; Power and Harrison 2005; Macdonald et al. 2008). There were similar investigations of the gendered dynamics of fisheries restructuring in other North Atlantic countries (see Appendix A).

The combined gendered effects of global overfishing, fishery closures, the commodification of fisheries and coastal areas and the related marginalization of small scale and subsistence fisheries, provided the impetus for the development of new networks of researchers and activists. Combined leadership was provided by the Women in Fisheries program of the International Collective in Support of Fishworkers (ICSF), the affiliated Gender, Globalization and Fisheries network and others. These networks sought to document and find ways to address the gendered dynamics and consequences of the neoliberal globalization of fisheries in countries of the South and the North, and to identify strategies for change (see Neis et al. 2005). A key theme in this work was the way commodification of fish and seafood invites us to treat fish as an object. Paraphrasing McMahon (2002, 204), Neis 
and Maneschy $(2005,248)$ argued, “[a] fish isn’t just a fish, it carries in it, and into us when we eat it, a host of social relationships such as those with the people who grow, harvest, or trade the fish and also with Nature, not in the abstract but with particular nonhuman others, things, and individual places. When we partake in food, we consume relationships." This ecofeminist critique of neoliberal capitalist globalization linked environmental degradation to gender inequality via the tendency for fisheries wealth to flow from shore to boats as overfishing and environmental degradation forced the investment of more and more wealth in order to catch the remaining fish. Resources for household reproduction and processing employment options dwindled as enterprise costs increased. This and neoliberal state policies and globalization supported the consolidation of ownership and control of resources, contributing to class, gender, racial and other inequalities. Taking the cod collapse in Atlantic Canada as their case, Bavington et al. (2004) used a feminist political ecological approach to argue for including both natural and social science insights in order to understand the relationship between environmental degradation and the oppression of women (see also, MacDonald et al. 2008).

Despite their ecofeminist/feminist political ecology roots, these explorations do not decenter human interests in the sense that attention to the other-than-human is mainly from the standpoint of women's needs and concerns (an exception is Roach 2000 who employed an ecofeminist analysis of stewardship to fisheries in Canada). As with much fishy feminist work elsewhere, attention is still rare to alternative ontologies and to how our relations with the other-than-human marine world contribute to gender and other inequalities and to environmental degradation (see Tsing 2016 for an analysis of the relationship between landbased environmental degradation and other inequalities), including violence against otherthan-humans (see Collard 2018). Furthermore, North Atlantic fishy feminists have tended to focus on relations between women and men rather than on gender diversity and 
intersectionality. Similarly, the history of colonialism and racism in the structuring of settler fisheries and in shaping the experiences of Indigenous peoples and international migrant fish workers in Canada and Europe have not received widespread attention (for exceptions see Muszynski 1996, 2005; Kafarowski 2004; Knott 2016; Harper 2018). Finally, North Atlantic feminist work has remained, until recently, largely separate from or marginalized within mainstream fisheries research, including research seeking to combine social and natural science insights to understand and improve governance (note the neglect of gender in Bavinck 2001, and in Stephenson et al. 2018). Its impact on policy-making and fisheries is limited to non-existent across much of the region. Where gender has been addressed within governance research is within two international special issues on gender and fisheries (Frangoudes and Gerrard 2018; Frangoudes et al. 2019). Gender is also included in the recent Manifesto on marine social science (Bavinck and Verrips 2020; Frangoudes et al. 2020). However, these sources remain largely human-centric. In short, despite the rich contribution of North Atlantic fishery feminists, there is more work to be done. In the next section, we discuss approaches that draw on feminist insights in thinking through human-fish relations and consider how an ecofeminist MTH lens could reorient the kinds of questions we ask in fisheries research and activism as we seek to deepen our knowledge and broaden its impact.

\section{A Sea of change: More-than-human fisheries}

Collard et al. (2015) describe the surge in research on conservation sparked by the concept of the Anthropocene as "a sea of change" (322). For fisheries and aquaculture research, the ontological reordering embedded in MTH approaches presents us with the opportunity for "a sea of change" in thinking through human-fish relations. Indigenous, decolonial and postcolonial contributions document ontologies that disrupt the dominant narrative of human centrism in human-fish relations. Based on her two case studies in the Inuvialuit Settlement Region in the Canadian Artic, Todd (2014) argues that Inuvialuit of Paulatuuq use an idea of 
"fish pluralities" to "negotiate the complex and dynamic pressures faced by humans, animals, and the environment" (217). She discusses how this worldview differs from the human/animal binary that shapes western ontology, by placing fish alongside and equal to humans and in continual active engagement with them. It also brings to the forefront the colonial histories that have (or have attempted to) erase, delegitimize, and discount these ways of knowing. In their work on how knowledge and communication practices are integral to how we understand the sea, Neilson and Marcos (2019) argue that the Global South is home to worldviews that provide ways of engaging, knowing, and thinking about fish and fishing communities that do not lead to mass destruction. They conclude that tensions between fisheries science and fishing communities' knowledge often arise from different ontological lenses, and therefore immersion within and equal treatment of the ontologies that inform these alternative kinds of knowledge are necessary.

There is also a literature on fish ontologies in Science and Technology Studies (STS). This literature maps out how different practices - economic, scientific, political, technological, managerial - produce multiple versions of fish, each refracted through institutional and knowledge practices. For example, focusing on conservation strategies for wild Atlantic salmon on the east coast of Canada, Daniels and Mather $(2017$, p.3) "ask 'what' and 'who' is being cared for in particular socio-material assemblages". They argue that conflicting interests (e.g., commercial fishing, sport fishing, fishing for food) have produced different versions of salmon on the Gander River that offer, in turn, different kinds of care for fish and the humans with whom they come into contact. Schoot (2019) thinks through how the making of salmon happens through human entanglement with space-making and containment in aquaculture in Newfoundland and Labrador, Canada. In a similar vein, using ethnographic methods to study aquaculture practices in Norway and Tasmania, Lien and colleagues (Law and Lien 2016, Lien 2018, Lien et al. 2020) show how the complex 
processes entailed in domestication create farmed salmon as sentient, reshaping fish as something worthy of care (also see Swanson 2017).

\section{Feminist Fish Ontologies}

Some, limited feminist scholarship on fish ontologies combines insights from STS with conceptions of care. Probyn (2016:11), for example, maps out an "affective oceanic habitus" that is least harmful to or better yet, cares for, fish and fish workers and that pays attention to how the human in the MTH is gendered, as well as racialized and classed. Thinking though the idea of care in relation to the more-than-human, Power (2015) puts Haraway and Gibson-Graham in conversation with ideas about feminist ethics of care in the critical animal studies literature. She argues that a feminist ethics of care can highlight how changes in conditions and arrangements of fisheries work alter the everyday moments of relating to fish — seeing, touching, smelling, killing fish — and how these experiences open or close possibilities for new ways of thinking about relating to and caring for fish.

Foley (2019) combines a feminist global economy approach with its focus on power dynamics, production and social reproduction with a world ecology, commodity frontier framework, which he terms "primary-ecological-production of the substance of life" (545), in his historical reanalysis of the Newfoundland and Labrador fishery. This allows him to move beyond discussions of reproduction that focus only on humans.

In an early example of ecofeminist fisheries research, Carolyn Merchant $(1997,1999)$ argued for a new ethic to guide fisheries management. She documented shifts in the ethics guiding fisheries management of the Euro-American fishery in the Pacific Northwest of the United States from neoliberal individualism to utilitarianism to ecocentrism, showing how each, in turn, has done much damage to fish and to marginalized communities and groups. In an analysis that foreshadows current critiques of the concept Anthropocene, she 
problematizes ecocentric approaches that take up "anthropocentric/nonanthropocentric" framings noting they mask "the role of economics, particularly the role of capitalism, placing the onus on human hubris and domination rather than on the capitalist appropriation of both nature and labor" (Merchant 1999, 20). Merchant $(1999,29)$ proposes instead a "partnership ethic" based on "mutual living interdependence" that is intersectional, decenters humans, yet is somewhat utilitarian in its focus on "the greatest good."

These literatures point to the complex network of changing relations between diverse groups of humans and fish in the context of particular forms of exploitation of ocean ecologies. They also point to a tension underpinning what is a theoretical divide between mainstream and most feminist fisheries literatures from the North Atlantic and ecofeminist MTH literature that decenters human interests. Roach (2000) raises the questions that get at this tension when she asks, "which is more important, the lifestyle of the fishers or the life of the fish?" (75). We ask, how do we, as feminist fisheries researchers address this tension? How might ecofeminist MTH analyses shed light on the origins and dynamics of current practices of relating to fish and each other within coastal communities and across global value chains that are based on extraction, oppression and the degradation of human and otherthan-human capacities? And how might ecofeminist MTH approaches join and support a conversation for how best to do this work? In the next section, we propose some directions to reorient future work in response to these questions.

\section{Future directions}

In making the case for an ecofeminist MTH approach to fisheries, we are not suggesting that other approaches cannot or should not be used. Instead, we are suggesting that applying an ecofeminist MTH lens to fisheries builds on the strengths of existing feminist fisheries research and offers a path to encompass attention to human-fish relations critical to the Anthropocene context in which we find ourselves. The existing body of feminist fisheries 
work foregrounds the ways in which neoliberal governance and capitalist economic structures intersect with patriarchal, colonial, racialized and classed gender orders to make invisible, and at the same time rely on, the work and bodies of diversely situated and shifting groups of women and fish in fisheries social-ecological systems. Some of this work has connected patriarchy and other systems of oppression to environmental degradation but there is more that needs to be done. We thus conclude by highlighting three ways that ecofeminist MTH approaches can extend and reorient future North Atlantic and other feminist fisheries research and activism.

First, an ecofeminist MTH approach shifts the focus to fish. How, where, when and with what consequences have fish come to be seen as part of Nature, and separate from humans? Rather than accepting fish as naturally commodified resources, the primary purpose of which is to support production for exchange to benefit (some) humans, ecofeminist MTH approaches point us towards explorations of how fish become resources and are commodified in the first place, with what consequences. They highlight patriarchal, colonial and capitalist processes that make invisible and exploit (some) human and animal labour and lives while simultaneously relying on and often enhancing historically constituted vulnerabilities. Collard and Dempsey's work (2017) is instructive here. They developed a framework for thinking through the different and often contradictory ways that capitalism relies on and enacts Nature. Their approach includes but also extends beyond commodification processes, highlighting the hidden ways in which Nature may benefit or threaten the interests of capital. Their approach and that of some others go beyond the practice of disrupting the animal/human or Nature/Culture binaries found, for example, in much of the literature on fisheries cyborgization that ignores gender (Johnsen et al. 2009). Ecofeminist MTH approaches direct attention instead to how capitalism, patriarchy, colonialism and other systems of oppression assemble in specific times, places, and spaces to differentiate and 
devalue fish and other marine life and transform them and the labour and social reproductive capacities of differently situated, gendered groups into commodities. Understanding how these systems of oppression operate, intersect and produce inequalities within and between species is especially important in the context of the enhanced volatility and vulnerabilities associated with intersecting global environmental change and the ever-deepening commodification of life and livelihoods.

Second, grounding analysis in the deeply entwined lives of people and other-thanhumans that depend on and live in places, mitigates tendencies to make universal claims. One of the strengths of feminist fisheries research is the commitment to starting from the lives of marginalized people who live and work in particular historically-constituted fishing places, while also attending to relationships that encompass ocean to plate. Indigenous and decolonial scholars offer direction on how to extend place-based methods to account for the more-than-human relations in the context of what Whyte $(2017,208)$ calls "industrial settler campaigns." Referring to examples of Anishinaabe restoration and conservation projects, Whyte $(2017,213)$ explains that "the focus on native species puts in perspective the convergence between deep Anishinaabe stories and histories and the more recent industrial settler degradation of the environment." Sundberg $(2014,39)$ suggests an approach whereby the researcher pays attention to "the embodied and emplaced movements involved in producing worlds" with the goal of fostering an openness to what Sami scholar Rauna Kuokkanen calls "multiepistemic literacy" (see Sundberg 2014). In the case of fisheries, this means starting in watery places - in oceans and rivers, along coasts, in aquaculture pens. These places are sites of "wet ontologies" (Steinberg and Peters 2015, 248), where living organisms are entangled and assembled within socionatural environments in ways that foster or constrain "abundant futures" (Collard et al. 2015, 323). Framed this way, place-based approaches have the potential to highlight the patchiness of biophysical-fish-fisheries-socio- 
cultural relationships in the context of colonial, patriarchal and capitalist fisheries and, in that patchiness, to develop strategies for achieving environmentally and socially "just sustainability” (Agyeman, Bullard, and Evans 2003 in Gibson-Graham et al. 2019, pg. 8).

Finally, building on the justice-oriented politics of feminist fisheries research, ecofeminist MTH approaches examine speciesism and anthroparchy as systems of oppression that harm animals, Nature, and social and more-than-human relations, while interacting and intersecting with other systems of oppression. This focus directs us to think about how to reorganise human-fish relations to support "the fullest expression of animal life, including capacity for movement, for social and familial association, and for work and play" (Collard et al. 2015, 328). It makes visible the ways in which fish and other marine life have been subjected to violence for the benefit of some human interests and allows space for rethinking oppression in much broader, more inclusive ways.

\section{Conclusion}

This paper identifies strengths and silences in North Atlantic fishy feminist work, proposes a stronger engagement with ecofeminist MTH literatures and provides some starting points for future work. As noted by one of our reviewers, feminist North Atlantic work has been mostly guided by feminist sociology and anthropology without much influence from human geography, including the MTH approaches. We are aware of the difficulty that exists in applying theoretical and abstract concepts to fisheries and aquaculture problems that must be negotiated within national and international governance structures. But we need conceptual tools to address the current threats facing our oceans, fish and other marine life, and the people who depend on them. Future work using an ecofeminist MTH framework can help us scrutinize and challenge the Blue Economy and Blue growth narratives advanced by many nations that seek to further commodify ocean capacity while adhering to the lofty equity and justice objectives of the United Nations Sustainable Development Goals. 


\section{Acknowledgements}

Research funding was provided by the Ocean Frontier Institute, through an award from the Canada First Research Excellence Fund.

\section{References}

Bavington, Dean, Brenda Grzetic, and Barbara Neis. 2004. "The feminist political ecology of fishing down: reflections from Newfoundland and Labrador." Studies in Political Economy 73(1): 159-182.

Bavinck, Maarten. 2001. Marine resource management: conflict and regulation in the fisheries of the Coromandel Coast. Sage Publications.

Bavinck, Maarten \& Jojada Verrips. 2020. Manifesto for the marine social sciences. Maritime Studies 19: 121-123. https://doi.org/10.1007/s40152-020-00179-x

Bennett, Nathan J. 2018. "Navigating a just and inclusive path towards sustainable oceans." Marine Policy 97: 139-146.

Collard, Rosemary-Claire. 2018. "Disaster capitalism and the quick, quick, slow unravelling of animal life." Antipode 50(4): 910-928.

Collard, Rosemary-Claire, Jessica Dempsey, and Juanita Sundberg. 2015. "A manifesto for abundant futures." Annals of the Association of American Geographers 105(2): 322-330. 
Collard, Rosemary-Claire, and Jessica Dempsey. 2017. "Capitalist natures in five orientations." Capitalism Nature Socialism 28(1): 78-97. DOI:

$10.1080 / 10455752.2016 .1202294$

Daniels, Jennifer, and Charles Mather. 2017. "Conservation and care: material politics and Atlantic salmon on Newfoundland's Gander River." Maritime studies 16(1): 17.

Davé, Neil. 2020. "Introducing Tidal: A moonshot to protect the ocean and feed humanity." Blog X. March 2, 2020. Accessed March 12, 2020 https://blog.X.company/introducing-tidal$\underline{1914257962 \mathrm{c} 3}$

Donkersloot, Rachel, Jesse Coleman, Courtney Carothers, Danielle Ringer, and Paula Cullenberg. 2020. "Kin, community, and diverse rural economies: Rethinking resource governance for Alaska rural fisheries." Marine Policy 117: 103966.

Evans, John. 2020. Seafood industry fears consequences of Boris Johnson's immigrant worker plan. Intrafish. February 20, 2020, Accessed on March 12, 2020, https://www.intrafish.com/trade/seafood-industry-fears-consequences-of-boris-johnsonsimmigrant-worker-plan/2-1-759328

Frangoudes, Katia, Gerrard, Sirri. 2018. “(En)Gendering Change in Small-Scale Fisheries and Fishing Communities in a Globalized World." Maritime Studies 17: 117-124. https://doi.org/10.1007/s40152-018-0113-9 
Frangoudes, Katia., Gerrard, Sirri. \& Kleiber, Danika. 2019. “Situated transformations of women and gender relations in small-scale fisheries and communities in a globalized world". Maritime Studies 18: 241-248. https://doi.org/10.1007/s40152-019-00159-w

Frangoudes, Katia, Siri Gerrard, and Alicia Said. 2020. "Commentary 6 to the Manifesto for the marine social sciences: gender and the role of women." Maritime Studies 1-2, doi:10.1007/s40152-020-00186-y

Foley, Paul. 2019. "Social-ecological reproduction and the substance of life in commodity frontiers: Newfoundland fisheries in world market shifts." Capital \& Class 43(4): 543-560.

FAO. 2017. "Towards gender-equitable small-scale fisheries governance and developmentA handbook. In support of the implementation of the Voluntary Guidelines for Securing Sustainable Small-Scale Fisheries in the Context of Food Security and Poverty Eradication." Nilanjana Biswas. Rome, Italy.

Gaard, Greta. 2011. "Ecofeminism revisited: Rejecting essentialism and re-placing species in a material feminist environmentalism." Feminist Formations 23(2): 26-53.

GAF. 2018. Gender And Fisheries. https://www.gafconference.org/about.htm

Gerrard, Siri, and Danika Kleiber. 2019. "Women fishers in Norway: few, but significant." Maritime Studies 18(3): 259-274, https://doi.org/10.1007/s40152-019-00151-4 
Gibson-Graham, J. K., Jenny Cameron, Stephen Healy, and Joanne McNeill. 2019. "Roepke lecture in economic geography_Economic geography, manufacturing, and ethical action in the Anthropocene." Economic Geography 95(1): 1-21.

Haraway, Donna. 2008. "Companion species, mis-recognition, and queer worlding." Queering the non/human: xxiii-xxxvi.

Harrison, Elizabeth, 1995. "Fish and feminists." ids bulletin, 26(3): 39-47.

Harper, Sarah, Dirk Zeller, Melissa Hauzer, Daniel Pauly, and Ussif Rashid Sumaila. 2013. "Women and fisheries: Contribution to food security and local economies." Marine policy 39: 56-63, https://doi.org/10.1016/j.marpol.2012.10.018.

Harper, Sarah, Anne K. Salomon, Dianne Newell, Pauline Hilistis Waterfall, Kelly Brown, Leila M. Harris, and U. Rashid Sumaila. 2018. "Indigenous women respond to fisheries conflict and catalyze change in governance on Canada's Pacific Coast." Maritime Studies 17(2): 189-198.

Johnsen, Jahn Petter, Peter Sinclair, Dean Bavington and Petter Holm. 2009. "The cyborgization of the fisheries: on attempts to make fisheries management possible." MAST 7 (2): 9-34.

Kafarowski, Joanna. 2004. "“" Everyone Should Have a Voice, Everyone's Equal": Gender, Decision-Making and Environmental Policy in the Canadian Arctic." Canadian Woman Studies 24(4): 12-17. 
Kleiber, Danika, Leila M. Harris, and Amanda CJ Vincent. 2015. "Gender and small-scale fisheries: A case for counting women and beyond." Fish and Fisheries 16(4): 547-562.

Knott, Christine. 2016. “Contentious Mobilities and Cheap(Er) Labour: Temporary Foreign Workers in a New Brunswick Seafood Processing Community." Canadian Journal of Sociology 41(3): 375-98.

Knott, Christine, and Barbara Neis. 2017. "Privatization, financialization and ocean grabbing in New Brunswick herring fisheries and salmon aquaculture." Marine Policy 80: 10-18. https://doi.org/10.1016/j.marpol.2016.10.022.

Law, John, and Marianne Elisabeth Lien. 2016. "The practices of fishy sentience." In Humans, Animals and Biopolitics: The more-than-human condition, Kristin Asdal, Tone Druglitrø \& Steve Hinchliffe (eds): 30-47.

Latour, Bruno. 2018. Down to earth: Politics in the new climatic regime. John Wiley \& Sons.

Lien, Marianne Elisabeth. 2020. "Dreams of Prosperity-Enactments of Growth: The Rise and Fall of Farming in Varanger." Anthropological Journal of European Cultures 29(1): 42-62.

Lien, Marianne, Heather Anne Swanson, and Gro Ween. 2018. "Introduction: Naming the Beast-Exploring the Otherwise." In Domestication Gone Wild, Swanson, Heather Anne, Marianne Elisabeth Lien, and Gro B. Ween (eds): 1-30. 
Maina-Okori, Naomi Mumbi, Jada Renee Koushik, and Alexandria Wilson. 2018.

"Reimagining intersectionality in environmental and sustainability education: A critical literature review." The Journal of Environmental Education 49(4): 286-296.

MacDonald, Martha, Barbara Neis, and Grant Murray. 2008. "State policy, livelihood protection and gender on Canada's East Coast." International Journal of Canadian Studies/Revue internationale d'études canadiennes 38: 149-180, https://doi.org/10.7202/040810ar.

Magra, Iliana. 2019. "Millions of Salmon in Norway Killed by Algae Bloom." The New York Times, May 23, 2019. Accessed March 12, 2020.

https://www.nytimes.com/2019/05/23/world/europe/salmon-norway-algae-bloom.html

McKenzie-Sutter, Holly. 2019. "Mass Salmon die-off in Newfoundland.” National Observer, October 13, 2019, accessed Nov. 18, 2019.

https://www.nationalobserver.com/2019/10/13/news/mass-salmon-die-newfoundland

Merchant, Carolyn. 1999. "Fish First! The Changing Ethics of Ecosystem Management.” In Northwest Lands, Northwest Peoples: Readings in Environmental History, edited by D.

Goble, Dale and W. Hirt, Paul, 295-308. Seattle: University of Washington Press.

Merchant, Carolyn. 1980. The death of nature. London: Wildwood House.

Mies, Maria and Vandana Shiva. 2014. Ecofeminism. [2nd edition]. London: Zed Books. 
Moore, Gareth. 2020. "Lower the bar for migrants says salmon processor."

FishFarmingExpert. February 5, 2020. Accessed on March 12, 2020,

https://www.fishfarmingexpert.com/article/lower-the-bar-for-migrants-says-salmon-

processor/

Mott, Carrie, and Daniel Cockayne. 2017. "Citation matters: mobilizing the politics of citation toward a practice of 'conscientious engagement'." Gender, Place \& Culture 24(7): 954-973.

Muszynski, Alicija.1996. Cheap Wage Labour: Race and Gender in the Fisheries of British Columbia. Montreal: McGill-Queen's University Press.

Mutter, Rachel. 2020. "Thousands of fish dead at Altantic Sapphire land-based salmon farm: High nitrogen levels appear to be the cause of the event at the company's Danish subsidiary." Intrafish. Accessed March 3, 2020, https://www.intrafish.com/aquaculture/thousands-of-fishdead-at-atlantic-sapphire-land-based-salmon-farm/2-1-765004

Nadel-Klein, Jane and Dona Lee Davis eds. 1988. To Work and To Weep: Women in Fishing Economies. St. John's: ISER.

Neilson, Alison Laurie, and Rita São Marcos. 2019. "Reframing marine resource management with relational ontologies and hybrid entanglements: Fishing for empathy between Azorean fishers and scientists." Marine Policy 105: 30-37. 
Neis, Barbara and Maria Christina Maneschy. 2005. "Moving Forward." In Changing tides: Gender, fisheries and globalization, Neis, Barbara, Marion Binkley, Siri Gerrard, and Maria Christina Maneschy (eds): 245-255.

Neis, Barbara, Marion Binkley, Siri Gerrard, and Maria Christina Maneschy. 2005. Changing tides: Gender, fisheries and globalization. http://toobigtoignore.net/wpcontent/uploads/2018/02/Changing-Tides-TEXT.pdf

Neis, Barbara, Siri Gerrard, and Nicole G. Power. 2013. "Women and children first: the gendered and generational social-ecology of smaller-scale fisheries in Newfoundland and Labrador and northern Norway." Ecology and Society 18 (4), https://doi.org/10.5751/ES06010-180464.

Noorani, Tehseen, and Julian Brigstocke. 2018. More-than-human participatory research. University of Bristol/AHRC Connected Communities Programme.

Patel, Raj, and Jason W. Moore. 2017. A history of the world in seven cheap things: A guide to capitalism, nature, and the future of the planet. California: University of California Press.

Pettersen, Liv Toril. 2019. "From household business to shareholding companies-impacts on gender relations and influence in fisheries and fish farming in northern Norway." Maritime Studies 18(3): 305-319, https://doi.org/10.1007/s40152-018-0122-8

Plumwood, Val. 2000. "Integrating ethical frameworks for animals, humans, and nature: A critical feminist eco-socialist analysis." Ethics \& the Environment, 5(2), pp.285-322. 
Porter, Marilyn. 1985. ""She Was Skipper of the Shore-Crew:" Notes on the History of the Sexual Division of Labour in Newfoundland.” Labour/Le Travail, 15, 105-123.

Power, Nicole Gerarda. 2005. What Do They Call a Fisherman?: Men, Gender, and Restructuring in the Newfoundland Fishery. St. John's: ISER

Power, Nicole Gerarda. 2015. "Reflections on a Feminist Care Approach to Rural Fisheries." In Feminisms and Ruralities, Barbara Jo Pini, Berit Brandth, and Jo Little (eds):143-54.

Probyn, Elspeth. 2014. "Women Following Fish in a More-than-Human World." Gender, Place and Culture 21(5): 589-603.

https://doi.org/10.1080/0966369X.2013.810597org/10.1080/0966369X.2013.810597.

Probyn, Elspeth. 2015. "Listening to fish: More-than-human politics of food." In NonRepresentational Methodologies, Phillip Vannini (ed): 82-98.

Probyn, Elspeth. 2016. Eating the Ocean. Durham: Duke University Press.

Probyn, Elspeth, Kate Johnston, and Nancy Lee (eds). 2020. Sustaining Seas: Oceanic Space and the Politics of Care. London: Rowman Littlefield.

Roach, Catherine, M. 2000. "Stewards of the Sea: A Model for Justice?” In Just Fish: Ethics and Canadian Marine Fisheries, Coward et al. (eds): 67-82. 
Schoot, Ignace. 2019. Opening up containment: making space in Newfoundland salmonid aquaculture. Diss. Memorial University of Newfoundland.

SEAFDEC. Southeast Asian Fisheries Development Center. http://www.seafdec.org/

Song, Andrew M., and Adam Soliman. 2019. "Situating human rights in the context of fishing rights-contributions and contradictions." Marine Policy 103: 19-26.

Steinberg, Philip. and Peters, Kimberly. 2015. "Wet ontologies, fluid spaces: Giving depth to volume through oceanic thinking." Environment and Planning D: Society and Space, 33(2), pp.247-264.

Stephenson, Robert L., Stacey Paul, Melanie Wiber, Eric Angel, Ashleen J. Benson, Anthony Charles, Omer Chouinard et al. 2018. "Evaluating and implementing social-ecological systems: A comprehensive approach to sustainable fisheries." Fish and Fisheries 19(5): 853873.

Sundberg, Juanita. 2014. "Decolonizing posthumanist geographies." cultural geographies 21(1): 33-47.

Swanson, Heather Anne.2017. "Methods for multispecies anthropology: thinking with salmon otoliths and scales." Social Analysis 61(2): 81-99. 
Szymkowiak, Marysia, and Melissa Rhodes-Reese. 2020. "Addressing the Gender Gap: Using Quantitative and Qualitative Methods to Illuminate Women's Fisheries Participation." Frontiers in Marine Science 7: 299.

Tiller, Rachel Gjelsvik, Lillian Hansen, Russell Richards, and Hillevi Strand. 2015. "Work segmentation in the Norwegian salmon industry: The application of segmented labor market theory to work migrants on the island community of Frøya, Norway." Marine Policy 51: 563572.

Todd, Zoe. 2014. "Fish pluralities: Human-animal relations and sites of engagement in Paulatuuq, Artic Canada”. ÉTUDES/INUIT/STUDIES, 38(1-2):217-238.

Todd, Zoe. 2016. "An indigenous feminist's take on the ontological turn:'Ontology'is just another word for colonialism". Journal of historical sociology, 29(1): 4-22.

Tsing, Anna. 2016. "Earth stalked by man." The Cambridge Journal of Anthropology 34(1): $2-16$.

Whatmore, Sarah. 2002. Hybrid geographies: Natures cultures spaces. London: Sage.

Whyte, Kyle Powys. 2017. “Our Ancestors' Dystopia Now: Indigenous Conservation and the Anthropocene." In Routledge Companion to the Environmental Humanities, Ursula Heise, Jon Christensen, and Michelle Niemann (eds), 206-2015. New York: Routledge.

Williams, Meryl J. 2012. “Gender Issues in Fisheries.” Issues 101: 26-28. 